\section{Improving Sensitivity of the Electrophoretic Mobility Shift Assay by Restricting Tissue Phosphatase Activities}

BioTechniques 24:964-670 (June 1998)

\begin{abstract}
Elucidating DNA-protein interactions at the molecular level is a prerequisite in understanding the way a transcriptionally active gene is regulated in various tissues. A number of techniques are presently available for this particular type of analyses, of which, the electrophoretic mobility shift assay (EMSA) is certainly the preferred one and likely the most sensitive and powerful. EMSA is widely used in combination with nuclear extracts obtained from cultured cells. However, its use with crude extracts prepared from whole animal tissues is still restricted. The restriction is partly due to numerous enzymatic activities, such as proteases and deacetylases, that strongly interfere with the EMSA's sensitivity. In addition to endogenous proteases, which can be inhibited by the addition of protease inhibitors to the buffers used, crude nuclear extracts obtained from whole animal tissues are often contaminated with considerable amounts of highly active endogenous phosphatases. Some of these enzymes substantially interfere with the ability of the EMSA to unravel specific DNA-protein interactions by removing the $5^{\prime}-[32 P]$ end-labeled phosphate of the DNA probe used for the binding assay. In this study, we evaluated whether we can restore the sensitivity of the EMSA by modifying the conditions under which the DNA-protein binding reaction is normally performed. Dephosphorylation by endogenous tissue phosphatases of the labeled probe used in our assays was drastically prevented by simply reducing both the temperature at which the binding reaction was normally performed and the time allowed for the DNA-protein interaction to occur.
\end{abstract}

\section{INTRODUCTION}

Elucidating DNA-protein interactions at the molecular level was found decades ago to be a prerequisite to the understanding of gene regulation both in vitro and in vivo. Consequently, a number of technical procedures were designed to locate where nuclear regulatory proteins bind along the regulatory sequences of those genes whose expression is allowed in a particular cell. DNA footprinting procedures such as DNaseI and Exonuclease III (Exo III) footprinting (1) were the first to appear. Both are based on the protection of the target DNA sequence bound by a specific transcription factor from the enzymatic digestion of the area of interest by DNaseI or Exo III. However, since an enzymatic reaction is required for both procedures to be completed, precisely adjusting the assay's parameters to reveal the protected areas might turn out to be a very difficult and time-consuming task. Furthermore, the fact that more than $50 \%$ of the target-site bearing labeled DNA molecules need to be occupied by the specific DNA-binding protein to yield a protected site in DNaseI footprinting might require as much as $75-100 \mu \mathrm{g}$ crude nuclear proteins, which renders the sensitivity of this procedure rather low.

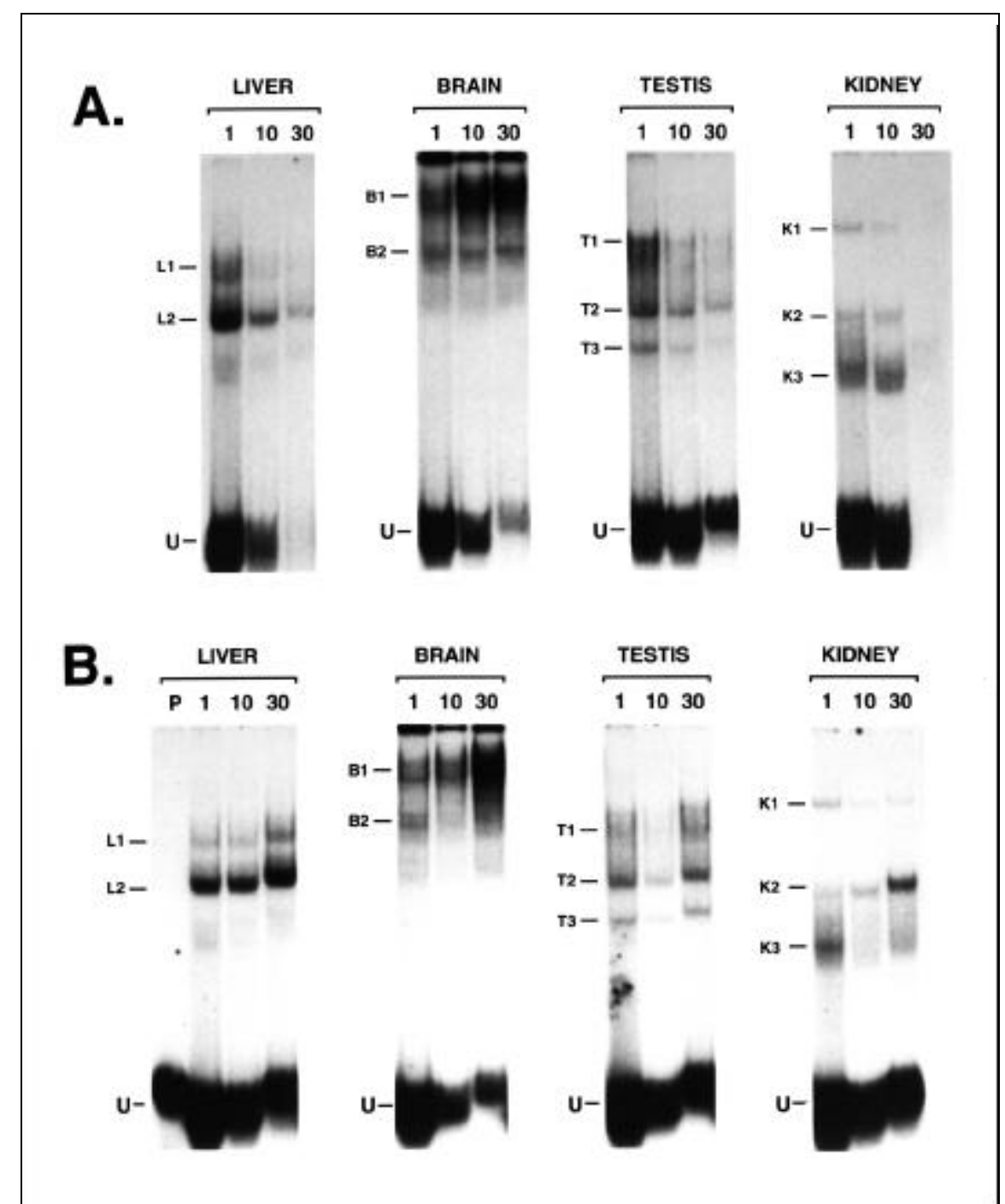

Figure 1. Effect exerted by both the temperature and the time of incubation on the formation of DNA-protein complexes in EMSA. The rGH silencer-1 labeled-probe (Sil1) was incubated with crude nuclear proteins obtained from various rat tissues (liver, brain, testis and kidney) and formation of DNAprotein complexes was evaluated by EMSA as detailed in Materials and Methods. Incubations proceeded at either $22^{\circ} \mathrm{C}(\mathrm{A})$ or $4^{\circ} \mathrm{C}(\mathrm{B})$ for various periods of time $(1,10$ and $30 \mathrm{~min})$. The position of the shifted complexes is shown (L1-L2, B1-B2, T1-T3 and K1-K3) along with that of the free probe (U). 
The electrophoretic mobility shift assay (EMSA) is undoubtedly one of the easiest and likely the most powerful procedure available to study DNA-protein interactions. EMSA is a very sensitive technique. Since it is based on the specific alteration in the electrophoretic mobility of the labeled DNA probe through its recognition by nuclear proteins upon autoradiography, as little as $0.5 \%$ binding to the target sequence is sufficient to yield a visible shifted complex in native polyacrylamide gel. Because of these particularly attractive properties, EMSA has become extremely popular as a complementary technique to gene expression studies. It is therefore not surprising that EMSA has led to the development of an impressive number of whole new and innovative procedures aimed at elucidating DNAprotein interactions over the last few years $(2,4,13,14,20)$. Most EMSA experiments are presently performed using nuclear protein preparations obtained either from primary cultures or established tissue-culture cells. The use of either crude or enriched nuclear extracts obtained from whole animal tissues obviously offers a major advantage as a source of material when further protein purification and isolation is anticipated. However, one major problem of selecting nuclear extracts from whole animal tissues as the source of proteins for the EMSA is the fact that some, if not all of them, are often contaminated with undesired enzymatic activities (including proteases, deacetylases, DNases and phosphatases), which can reduce considerably the sensitivity of the assay. Tissue protease and DNase activities are well documented and can easily be prevented from interfering with the sensitivity of these assays by supplying the reaction buffer with inhibitors specific for these activities.

In addition to these enzymes, most tissues are known to express one or more of the various types of tissue phosphatases that have been reported to date. These include enzymes that are expressed either in a tissue-specific manner, such as the rat bone/liver/kid-

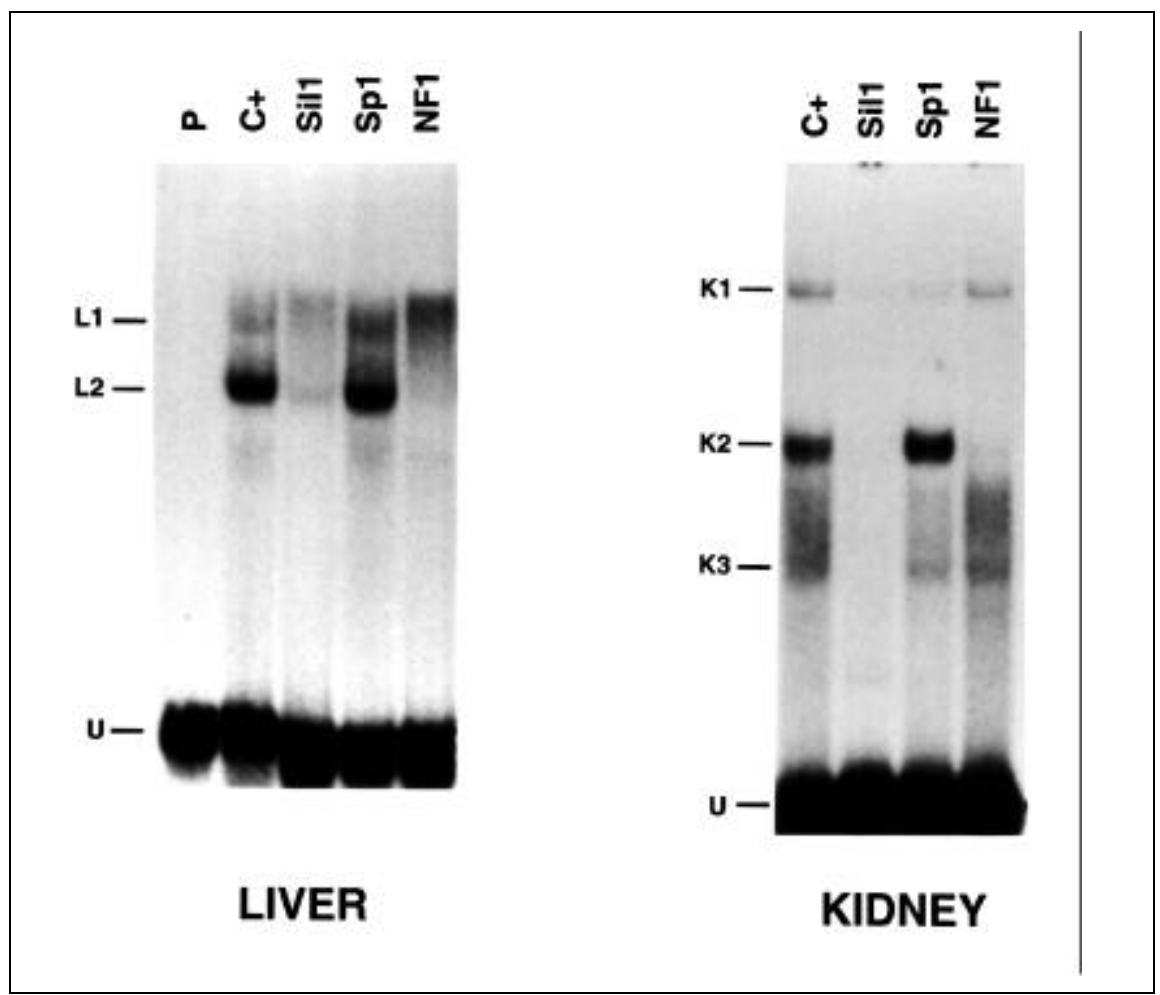

Figure 2. Competitions in EMSA. Crude nuclear proteins from rat liver and kidney were incubated with the Sil1-labeled probe either with no competitor $(\mathrm{C}+)$ or with a 500-fold molar excess of double-stranded oligonucleotides bearing the DNA sequence of Sil1 or that recognized by the transcription factors Sp1 and NF1. Incubation proceeded at $4^{\circ} \mathrm{C}$ for $10 \mathrm{~min}$. The position of the L1, L2, K1, K2 and K3 DNA-protein complexes is provided along with that of the free probe $(\mathrm{U})$. P: probe with no proteins added. 


\section{Short Technical Reports}

ney/placenta alkaline phosphatase (AP) (21) or the members of the acid phosphatase family [which comprise the prostate acid phosphatase (PAP) (11)] or in a non-tissue-specific manner, such as the tissue nonspecific alkaline phosphatase (TNAP) (8). Tissues such as the liver, the kidney and the bone have been reported to be rich in these enzymes [particularly the AP type (12)]. Most of the phosphatase activity is localized to the cytoplasm, yet a substantial portion of these enzymes (which also comprises AP) has been found in cell nuclei $(9,18,19)$. This explains why most nuclear extracts get contaminated by these enzymes in the course of their preparation. Because contaminating tissue APs have the ability to dephosphorylate the $5^{\prime}$ end of the labeled DNA probes that are normally used in EMSA (6), it is likely that these activities will drastically lower the EMSA's sensitivity by preventing the detection of the la- beled signal corresponding to gel-shifted, DNA-protein complexes. In this study, we evaluated the influence that contaminating phosphatases from various whole rat tissues might have on the specific detection of DNA-protein complexes in EMSA and propose noninvasive procedures that can be selected to restore the assay's sensitivity at no further expense and without any modification in the composition of the buffer system used for the assay.

\section{MATERIALS AND METHODS}

\section{Electrophoretic Mobility Shift Assays}

The double-stranded oligonucleotide Sil1 (5'-GATCCAAACGATGGTACCCTGCCAGAGTATCCTA-3'), containing the proximal silencer-1 element (Sil1) from the rat growth hormone gene that also bears a binding site for the rat liver NF1-L transcription factor (15), was synthesized and $5^{\prime}$ end-labeled using T4 Polynucleotide Kinase (Amersham Pharmacia Biotech, Baied'Urfé, QC, Canada) and [ $\gamma^{-32}$ P]dATP (NEN Life Science Products, Boston, MA, USA). Crude nuclear extracts were prepared from whole rat tissues (liver, brain, testis and kidney) as previously described (7). For EMSA, $2.5 \times 10^{4}$ counts per minute $(\mathrm{cpm})$ of the labeled Sill probe was incubated for 1,10 or 30 min at $4^{\circ}$ or $22^{\circ} \mathrm{C}$ (as specified in the Figure 1 legend), with $10 \mu \mathrm{g}$ of either of the above-mentioned tissue extracts, in the presence of $1.2 \mu \mathrm{g}$ poly $(\mathrm{dI}-\mathrm{dC})$ (Amersham Pharmacia Biotech) and 50 $\mathrm{mM} \mathrm{KCl}$ in Buffer D $(20 \mathrm{mM} \mathrm{N}$-[2hydroxyethyl]piperazine- $N$-[2-ethanesulfonic acid], $\mathrm{pH}$ 7.9, 20\% glycerol, $0.2 \mathrm{mM}$ ethylenediaminetetraacetic acid, $0.5 \mathrm{mM}$ phenylmethylsulfonyl fluoride). The reaction mixtures were then 
loaded on a $10 \%$ native polyacrylamide gel and subjected to electrophoresis against Tris-glycine buffer (1). Gels were dried and autoradiographed at $-80^{\circ} \mathrm{C}$. The signals corresponding to both the free probe and the shifted complexes were quantified by analysis on a PhosphorImager ${ }^{\mathrm{TM}}$ (Molecular Dynamics, Sunnyvale, CA, USA).

\section{Competition Experiments}

For competition experiments in EMSA, similar conditions as above were used, except that the labeled Sil1 probe was incubated for $10 \mathrm{~min}$ at $4^{\circ} \mathrm{C}$ with $10 \mu \mathrm{g}$ of crude nuclear extracts from rat liver or kidney, in the presence of a 500-fold molar excess of either of the following unlabeled double-stranded oligonucleotides: Sil1, Sp1 (bearing the high-affinity binding site for the positive transcription factor $\mathrm{Sp} 1$ [5'-GATCATATCTGCGGGGCGGGGCAGACACAG-3' (3)]) or NF1 (bearing the target sequence for human HeLa CTF/NF1 in adenovirus type 2 [5'-GATCTTATTTTGGATTGAAGCCAATATGAG-3' (5)]).

\section{RESULTS AND DISCUSSION}

\section{Formation of Specific DNA-Protein Complexes is Affected by the Length of the Incubation Period}

Phosphatase activities (particularly AP) are known to be very important in tissues such as the liver, the bone and the kidney (21). Because these phosphatases select the $5^{\prime}-\left[{ }^{32} \mathrm{P}\right]$-end-labeled probes used in EMSA as their substrate, they have been recently suggested to interfere with the sensitivity of the EMSA (6). To evaluate the extent of such a detrimental influence exerted by tissue phosphatases, crude nuclear extracts were prepared from various rat tissues (liver, brain, testis and kidney) and tested in EMSA for periods of time ranging from 1-30 min. The target DNA sequence used as the labeled probe consisted of a synthetic, double-stranded oligonucleotide bearing the binding site for the rat liver form of the transcription factor NF1 (termed NF1-L) that has been identified in Sill from the rat growth hormone gene promoter (15). This NF1 binding site-bearing oligomer has been previously reported to also bind other members of the NF1 family of transcription factors that are expressed in tissues such as the liver, the kidney, the testis and the lung (10,15-17).

As shown on Figure 1A, incubation of the Sil1-labeled probe with crude nuclear proteins prepared from whole rat liver yielded two distinct DNA-protein complexes (L1 and L2) easily detectable after only 1 min of incubation at $22^{\circ} \mathrm{C}$. However, allowing the binding reaction to proceed further up to $30 \mathrm{~min}$ (which is the average, widely used period of incubation in EMSA) resulted in a drastic reduction of the labeled signals corresponding to both the bound and the free probe. This vanishing effect likely reflects extensive dephosphorylation of the labeled probe by contaminating tissue phosphatases (6), ultimately leading to total, and nearly total, disappearance of the shifted L1 and L2 signals, respectively. An even more drastic decrease in signal strength is observed when crude nuclear proteins from rat kidney are incubated with the labeled probe for the same period of time. Indeed, all three shifted DNA-protein complexes (K1, K2 and $\mathrm{K} 3$ ), and the free probe itself, became totally undetectable after $30 \mathrm{~min}$ of incubation at $22^{\circ} \mathrm{C}$. A similar, but somehow less intense, loss of signal is also observed with the testis nuclear extract, whereas no such phosphatase activity is apparently interfering with the detection of DNA-protein complexes when crude nuclear proteins from rat brain are used. These results suggest that action of the tissue phosphatases is negligible when only $1 \mathrm{~min}$ of incubation is used to allow DNA-protein interaction. Such a short time of incubation is obviously sufficient to allow binding of nuclear proteins to their target sequence in vitro at $22^{\circ} \mathrm{C}$ (but not when the temperature is brought down to $4^{\circ} \mathrm{C}$, see Figure 1B). Furthermore, the above results provide evidence that probe dephosphorylation does not occur equally when nuclear extracts from different tissues are used. This is consistent with previously published studies in which both the kidney and the liver, but not the testis nor the brain, were reported to express high levels of TNAP in species such as human, mouse, rat and rabbit $(8,21)$. 


\section{Short Technical Reports}

\section{Lowering the Temperature of Incubation Reduces Target Probe Dephosphorylation}

Since most enzymatic activity is usually impaired when reducing the temperature at which the reaction is performed, we tested whether performing the binding reaction at $4^{\circ} \mathrm{C}$ would significantly affect the strength of the shifted complexes identified in Figure 1A. As Figure 1B indicates, the labeled probe used for the binding sustained very little dephosphorylation even when the incubation period extended up to $30 \mathrm{~min}(50 \%$ of the labeled probe remaining at $4{ }^{\circ} \mathrm{C}$ compared with $9 \%$ at $22^{\circ} \mathrm{C}$ in liver and $65 \%$ compared with only $1 \%$ at both $4^{\circ}$ and $22^{\circ} \mathrm{C}$, respectively, in kidney, as evaluated by PhosphorImager analyses [data not shown]), suggesting that most of the contaminating tissue phosphatases were unable to function properly at $4^{\circ} \mathrm{C}$. Consequent- ly, formation of complexes with the liver, the testis and the kidney extracts was recovered to levels very similar to those obtained when only $1 \mathrm{~min}$ of incubation was allowed at $22^{\circ} \mathrm{C}$ (Figure 1A). PhosphorImager analyses of the labeled signals corresponding to both the shifted DNA-protein complexes and the free probe indicated that performing the incubation for $30 \mathrm{~min}$ at $4^{\circ} \mathrm{C}$ rather than $22^{\circ} \mathrm{C}$ resulted in a 5-fold increase $\left(61190 \mathrm{U} / \mathrm{mm}^{2}\right.$ compared with $13307 \mathrm{U} / \mathrm{mm}^{2}$ ) in the sensitivity of the EMSA to detect the L2 complex (data not shown). The recovery in the binding of $\mathrm{K} 2$ to the Sil1-labeled probe when similar binding conditions are selected is even more impressive, resulting in a 60-fold increase (29639 U/ $\mathrm{mm}^{2}$ compared with $496 \mathrm{U} / \mathrm{mm}^{2}$ ) in the EMSA's sensitivity to detect this kidney-specific, DNA-protein complex at $4^{\circ} \mathrm{C}$ (data not shown).

To verify whether some of the com- plexes whose formation is affected by the binding conditions used above were truly interacting with the Sill-labeled probe in a specific manner, competition experiments in EMSA were conducted. Unlabeled double-stranded oligonucleotides bearing various transcription factors binding sites ( $\mathrm{Sp} 1$ and NF1) were used as unlabeled competitors, along with unlabeled Sil1. As shown in Figure 2, formation of both the liver L2 and the kidney K2 complexes was readily prevented by a 500 -fold molar excess of the Sil1 and NF1 oligomers, but not at all by a similar excess of the $\mathrm{Sp} 1$ oligonucleotide, confirming that L2 and $\mathrm{K} 2$ result from the recognition of the labeled probe by a member of the NF1 family $(10,15,17)$. Interestingly, formation of both $\mathrm{K} 1$ and $\mathrm{K} 3$ was efficiently prevented by Sill but not by the Sp1 and NF1 target site-bearing oligomers, indicating that nuclear transcription factors other than NF1 also possess 
the ability to interact with the Sil1-labeled probe.

We conclude from our results that alkaline phosphatases from tissues such as the kidney or the liver can indeed strongly impair the sensitivity of the EMSA when formation of the DNAprotein complexes is allowed to proceed for $30 \mathrm{~min}$, which is a standard incubation period in EMSA. However, we provided evidence that performing the assay for no more than a few minutes at room temperature (in this case, $22^{\circ} \mathrm{C}$ ) is clearly sufficient to allow the formation of any specific DNA-protein complex and to prevent the deleterious influence normally exerted by tissue APs. Alternatively, very similar results can be achieved by performing the binding reaction for $30 \mathrm{~min}$ but at $4^{\circ} \mathrm{C}$. These alternatives allow for efficient re- covery of the EMSA's sensitivity at no additional cost and without modifying the composition of the buffer system selected, as would be unavoidable when phosphatase inhibitors are added to the binding buffer.

\section{REFERENCES}

1.Ausubel, F.M., B. Roger, R.E. Kingston, D.D. Moore, J.G. Seideman, J.A. Smith and K. Struhl. 1987. Current Protocols in Molecular Biology. Greene Publishing Associates and Wiley-Interscience, New York.

2.Chen, M., A. Laszlo, J.L.R. Roti and C.R. Hunt. 1996. Detection of single-base mutations by a competitive mobility shift assay. Anal. Biochem. 239:61-69.

3.De Vries, E., W. Van Driel, S.J.L. Van den Heuvel and P.C. Van der Vliet. 1987. Contact analysis of the HeLa nuclear factor 1 recognition site reveal symmetrical binding at one site of the DNA helix. EMBO J. 6:161168.

4.Dyer, R.B. and N.K. Herzog. 1995. Immunodepletion EMSA: a novel method to identify proteins in a protein-DNA complex. Nucleic Acids Res. 23:3345-3346.

5.Dynan, W.S. and R. Tjian. 1983. The promoter-specific transcription factor $\mathrm{Sp} 1$ binds to upstream sequences in the SV40 early promoter. Cell 35:79-87.

6.Fenton, C. and M.R. El-Gewely. 1997. Pyrophosphate in the binding reaction increases the sensitivity of mobility shift analysis. BioTechniques 23:248-250.

7.Graves, B.J., P.F. Johnson and S.L. McKnight. 1986. Homologous recognition of a promoter domain common to the MSV LTR and HSV Tk gene. Cell 44:565-576.

8.Hoshi, K., N. Amizuka, K. Oda, Y. Ikehara and H. Ozawa. 1997. Immunolocalization of tissue non-specific alkaline phosphatase in mice. Histochem. Cell Biol. 107:183-191.

9.Kenter, A.L. and L. Morgan. 1995. Mitogenic activation of a nuclear alkaline phosphatase in normal activated lymphocytes. J. Immunol. 154:2041-2050.

10.Leclerc, S., W. Eskild and S.L. Guérin. 1997. The rat growth hormone and human cellular retinol binding protein 1 genes share homologous NF1-like binding sites that exert either positive or negative influences on gene expression in vitro. DNA Cell Biol. 16:951967.

11.Lin, M.F., S.S. Li, T.M. Chu and C.L. Lee. 1990. Comparison of prostate acid phosphatase with acidic phosphatase isoenzymes from the lung and spleen. J. Clin. Lab. Anal. 4:420-425

12.McComb, R.B., G.N. Bowers and S. Posen. 1979. Alkaline Phosphatase. Plenum Press, New York.

13.Novak, U. and L. Paradiso. 1995. Identification of proteins in DNA-protein complexes after blotting of EMSA gels. BioTechniques 19:54-55.

14.Orchard, K. and G.E. May. 1993. An EMSA-based method for determining the molecular weight of a protein-DNA complex. Nucleic Acids Res. 21:3335-3336.

15.Roy, R.J., P. Gosselin, M.J. Anzivino, D.D. Moore and S.L. Guérin. 1992. Binding of a nuclear protein to the rat growth hormone silencer element. Nucleic Acids Res. 20:401408.

16.Roy, R.J., P. Gosselin and S.L. Guérin. 1991. A short protocol for micro-purification of nuclear proteins from whole animal tissue. BioTechniques 11:770-777.

17.Roy, R.J. and S.L. Guérin. 1994. The 30$\mathrm{kDa}$ rat liver transcription factor nuclear factor 1 binds the rat growth hormone proximal silencer. Eur. J. Biochem. 219:799-806.

18.Vergnes, H.A., A. Brisson-Lougarre, J.G. Grozdea, C.J. Blum, Y. Kihn and J. Sevely. 1992. Nuclear localization and characterization of alkaline phosphatase in neutrophils from normal controls and pregnant women. Am. J. Hematol. 39:249-256.

19.Wilson, M.J. and K. Ahmed. 1976. Presence and androgen control of an alkaline phosphatase in the nucleus of rat ventral prostate. Biochim. Biophys. Acta 429:439-447.

20.Yamamoto, H. 1997. DNA mobility shift assay coupled with SDS-PAGE for detection of DNA-binding proteins. BioTechniques 22:210-211.

21.Zernik, J., B. Kream and K. Twarog. 1991. Tissue-specific and dexamethasone-inducible expression of alkaline phosphatase from alternative promoters of the rat bone/liver/kidney/placenta gene. Biochem. Biophys. Res. Commun. 176:1149-1156.

The authors wish to thank Steeve Leclerc for his precious help in the preparation of the crude nuclear extracts that have been used in this study. M.A. Laniel is supported by a Studentship from the 'Fondation de l'Université Laval'. S. Guérin is a Senior Scholar from the 'Fonds de la Recherche en Santé du Québec' (FRSQ). This work was supported by a grant from the 'Natural Sciences and Engineering Research Council of Canada' (NSERC) to S.L.G. Address correspondence to Dr. Sylvain L. Guérin, Laboratory of Molecular Endocrinology, CHUL Research Center, 2705 Laurier Blvd., SteFoy (Québec) G1V 4G2, Canada. Internet: sylvain.guerin@crchul.ulaval.ca

Received 12 December 1997; accepted 12 February 1998.

\section{Marc-André Laniel and Sylvain L. Guérin CHUL Research Center Québec, QC, Canada}

